Check for updates

Cite this: RSC Adv., 2018, 8, 8528

Received 6th January 2018

Accepted 18th February 2018

DOI: $10.1039 / \mathrm{c} 8 \mathrm{ra00158h}$

rsc.li/rsc-advances

\section{Synthesis of nitrogen doped carbon quantum dots/ magnetite nanocomposites for efficient removal of methyl blue dye pollutant from contaminated water $\dagger$}

\author{
Aschalew Tadesse, ${ }^{\text {ac }}$ Dharmasoth RamaDevi, ${ }^{\text {b }}$ Mabrahtu Hagos, (iD ad \\ GangaRao Battu ${ }^{\mathrm{b}}$ and K. Basavaiah (iD) *a
}

\begin{abstract}
As a remedy for environmental pollution, a simple synthesis approach has been developed to prepare nitrogen doped carbon quantum dot/magnetite nanocomposites ( $\mathrm{Fe}_{3} \mathrm{O}_{4}(\mathrm{NNCQDs} N C s)$ using non-toxic and cost effective lemon juice as precursor for removal of organic dye pollutant. $\mathrm{Fe}_{3} \mathrm{O}_{4}$ @NCQDs NCs were characterized by using UV-Vis spectroscopy, FTIR, XRD, FESEM, EDS, TEM, VSM and TGA/DTA. TEM results show spherical shaped $\mathrm{Fe}_{3} \mathrm{O}_{4} \mathrm{aNCQDs} \mathrm{NCs}$ with an average particle size of $5 \mathrm{~nm}$. Batch adsorption studies were done to investigate the tendency of the nanocomposites to remove representative methyl blue (MB) dye from aqueous solution. The effects of $\mathrm{MB}$ dye concentration, dosage of $\mathrm{Fe}_{3} \mathrm{O}_{4} @ \mathrm{NCQDS} \mathrm{NC}$ adsorbent, $\mathrm{pH}$, contact time and temperature were optimized by varying one variable while all the other parameters were kept constant. The experiment showed rapid removal of MB dye within 20 minutes with an adsorption efficiency of over $90.84 \%$ under optimum conditions. The adsorption process fits the Freundlich isotherm model well with $R^{2}$ and $n$ values of 0.993 and 1.842 , respectively, at $298 \mathrm{~K}$ indicating the feasibility of the adsorption process. The adsorption process is spontaneous and involves exothermic behaviour as confirmed by thermodynamic studies. From a kinetic study, it was found that the pseudo-second order model is more suitable to describe the adsorption process than the pseudo-first order model for adsorption of MB dye onto $\mathrm{Fe}_{3} \mathrm{O}_{4} @ \mathrm{aNCQDS} \mathrm{NCs}$.
\end{abstract}

\section{Introduction}

During the past decades, the release of large quantities of toxic, carcinogenic and non-biodegradable organic dye pollutants into aquatic systems has continuously increased due to rapid industrialization, civilization and agricultural activity. ${ }^{1}$ The presence of organic dye pollutants even at trace levels in effluents is very dangerous to human and aquatic life. The organic dye pollutants remain highly visible, resistant to aerobic digestion and stable to oxidizing agents due to their complex chemical structure and synthetic origin. ${ }^{2}$ Therefore, it is highly desirable to develop an environmental friendly, highly efficient

\footnotetext{
aDepartment of Inorganic and Analytical Chemistry, Andhra University, Visakhapatnam-530003, India. E-mail: klbasu@gmail.com

${ }^{b} A U$ College of Pharmaceutical Sciences, Andhra University, Visakhapatnam-530003, India

'Department of Applied Chemistry, Adama Science and Technology University, Adama1888, Ethiopia

${ }^{d}$ Faculty of Natural and Computational Sciences, Woldia University, Woldia-40o, Ethiopia

$\dagger$ Electronic supplementary information (ESI) available: Emission spectra of NCQDs, EDS and TGA/DTA data, magnetization curve, tables for isotherm parameters, thermodynamic and kinetic data. See DOI: 10.1039/c8ra00158h
}

and cost effective method for removal of organic dye pollutants from wastewater effluents even at trace levels.

Different treatment methods such as biological treatment, ${ }^{3}$ flocculation-coagulation, ${ }^{4}$ adsorption, ${ }^{5}$ membrane filtration ${ }^{6}$ and oxidation ${ }^{7}$ have been used to remove dyes from wastewater effluents. Among these methods, the adsorption method is the simplest, efficient and low cost method for removal of dyes from wastewater effluents with no generation of byproducts and various natural and synthetic materials have been used as adsorbents. ${ }^{\mathbf{8} 9}$ Recently, nanoscience and nanotechnology research introduced nanoadsorbent with more efficient adsorption, low cost and recyclable properties. The most repeatedly investigated nanoadsorbent is magnetite nanoparticles $\left(\mathrm{Fe}_{3} \mathrm{O}_{4} \mathrm{NPs}\right)$ based nanomaterials due to their excellent magnetic, biocompatible properties, facile synthesis and ease with which they may be tuned and functionalized for specific applications. ${ }^{10,11}$ Moreover, the most important advantage of $\mathrm{Fe}_{3} \mathrm{O}_{4}$ NPs is its easy separation and purification after application by an external magnet due to its magnetic properties..$^{12,13}$ However, bare $\mathrm{Fe}_{3} \mathrm{O}_{4}$ NPs could easily aggregate in aqueous system to reduce the energy associated with surface area to volume ratio and the strong dipole-dipole attraction between particles and easily undergo oxidation and thus limits their 
technological applications. ${ }^{\mathbf{1 4 , 1 5}}$ To effectively use the advantage of $\mathrm{Fe}_{3} \mathrm{O}_{4}$ NPs for technological applications, researchers have been continuously designing the aggregate free $\mathrm{Fe}_{3} \mathrm{O}_{4} \mathrm{NPs}$ via surface modification and functionalization. ${ }^{\mathbf{1 6 - 1 8}}$

A wide range of chemicals such as chitosan, activated carbon, polymers, graphene quantum dots, graphene oxide, multiwall carbon nanotubes, etc. have been employed for preparation of $\mathrm{Fe}_{3} \mathrm{O}_{4}$ NPs based nanocomposites for pollution abatement. ${ }^{19-23}$ In preparation of $\mathrm{Fe}_{3} \mathrm{O}_{4}$-chitosan nanocomposites, the surface of magnetite modified with amine and hydroxyl groups on chitosan. ${ }^{24}$ As a class of newly emerging fluorescent nanomaterials, carbon quantum dots (CQDs) have offered tremendous opportunities for a wide scope of applications due to its excellent properties like good stability and solubility in water, low cost and biocompatibility. ${ }^{25,26}$ Tremendous promise has been shown in different applications by compositing carbon quantum dots with nanoparticles. ${ }^{27}$ Similar to chitosan, nitrogen doped carbon quantum dots have reactive amine and hydroxyl groups which are amenable to chemical modifications and therefore, in nanocompositing $\mathrm{Fe}_{3} \mathrm{O}_{4}$ with nitrogen doped carbon quantum dots (NCQDs), amine and carboxyl groups on NCQDs modify the surface of $\mathrm{Fe}_{3} \mathrm{O}_{4}$ and protect the nanocomposites from aggregation. In addition, nitrogen doped carbon quantum dots (NCQDs) can preserve structural stabilization of $\mathrm{Fe}_{3} \mathrm{O}_{4}$ NPs as capping agent and improve the surface of the materials by providing important functional groups which are important for interaction of the nanocomposites with chemical pollutant in environment. ${ }^{28}$

In this paper, we report the design and synthesis of magnetic and eco-friendly $\mathrm{Fe}_{3} \mathrm{O}_{4} @ N C Q D$ NCs via coprecipitation using lemon juice as precursor. The as prepared $\mathrm{Fe}_{3} \mathrm{O}_{4} @ N C Q D s$ NCs have been applied for efficient removal of methyl blue (MB) dye from contaminated water. The effects of various experimental conditions such as contact time, initial concentration, $\mathrm{pH}$, temperature and adsorbent dosages on the removal efficiency of MB were evaluated through a batch adsorption experiments.

\section{Experimental section}

\subsection{Chemicals and reagents}

Iron(III) chloride hexahydrate $\left(\mathrm{FeCl}_{3} \cdot 6 \mathrm{H}_{2} \mathrm{O}\right)$ and iron(II) sulphate heptahydrate $\left(\mathrm{FeSO}_{4} \cdot 7 \mathrm{H}_{2} \mathrm{O}\right)$ were purchased from Merck, India. Fresh lemon fruits were purchased from the local store nearby Andhra University. $100 \mathrm{~mL}$ stainless steel Teflon lined autoclave was used for hydrothermal synthesis of NCQDs. Milli-Q water was used throughout the experiments. Ethylenediamine was purchased from LOBA Chemie, Mumbai, India. All the reagents used are analytical grade and used as received without any further purification.

\subsection{Synthesis of NCQDs from lemon juice}

Hydrothermal method was used to synthesis nitrogen doped carbon quantum dots (NCQDs) by taking $20 \mathrm{~mL}$ of lemon juice and $2 \mathrm{~mL}$ of ethylenediamine in a $100 \mathrm{~mL}$ Teflon-lined stainless steel autoclave and heated at $200{ }^{\circ} \mathrm{C}$ in furnace for 3 hours. The obtained black paste was dissolved in $15 \mathrm{~mL}$ of water and centrifuged at $3000 \mathrm{rpm}$ for 15 minutes to remove insoluble matter. Dichloromethane was added to the brown solution formed and centrifuged at $3000 \mathrm{rpm}$ for 20 minutes to remove unreacted organic moieties. The aqueous layer was separated from lower organic layer and centrifuged at $12000 \mathrm{rpm}$ for 20 minutes thrice to remove larger size particles and the brown yellowish solution was finally obtained. To further get the smaller particle size of NCQDs, cleaning was done using column chromatographic separation in help of silica gel and dichloromethane as solvent. The resulting NCQDs was characterized and used for preparation of novel $\mathrm{Fe}_{3} \mathrm{O}_{4} @$ @NCQDs NCs.

\subsection{Synthesis of $\mathrm{Fe}_{3} \mathrm{O}_{4}$ @NCQDs NCs}

Syntheses of $\mathrm{Fe}_{3} \mathrm{O}_{4}$ @NCQDs NCs were done via coprecipitation reaction. In the procedure, $100 \mathrm{~mL}$ aqueous solution of $2: 1$ molar ratio of metal salts $\mathrm{Fe}^{3+}\left(1.1127 \mathrm{~g} \mathrm{FeCl}_{3} \cdot 6 \mathrm{H}_{2} \mathrm{O}\right)$ and $\mathrm{Fe}^{2+}$ $\left(0.5708 \mathrm{~g} \mathrm{FeSO}_{4} \cdot 7 \mathrm{H}_{2} \mathrm{O}\right)$ was added in $250 \mathrm{~mL}$ three neck round bottom flask and the reaction was carried out for one hour under constant stirring in atmospheric nitrogen at $80{ }^{\circ} \mathrm{C}$. To the reaction flask, $25 \mathrm{~mL}$ diluted NCQDs aqueous solution (5 $\mathrm{mg}$ $\mathrm{mL}^{-1}$ and $10 \mathrm{mg} \mathrm{mL}^{-1}$ ) was added and reaction continued for 30 minutes. Then $20 \mathrm{~mL}$ of $2 \mathrm{M} \mathrm{NaOH}$ was added drop wise. The reaction was allowed to continue under stirring for 2 hours at $80^{\circ} \mathrm{C}$. Finally, the black precipitate was obtained and separated by decantation with help of external magnet, washed several times with Milli-Q water, and dried under vacuum at room temperature. Bare $\mathrm{Fe}_{3} \mathrm{O}_{4}$ NPs was synthesized in the same procedure without using NCQDs.

\subsection{Characterization}

UV-Vis absorption spectra of the synthesised NCQDs, $\mathrm{Fe}_{3} \mathrm{O}_{4} \mathrm{NPS}$ and $\mathrm{Fe}_{3} \mathrm{O}_{4} @$ @CQDs NCs were obtained using a UNICAM UV 500(Thermo Electron Corporation). Fourier transform infrared spectra (FTIR) were obtained over the range of $400-4000 \mathrm{~cm}^{-1}$ using a SHIMADZU-IR PRESTIGE-2 Spectrometer. X-ray powder diffraction (XRD) pattern were recorded using PANalyticalX'pert pro diffractometer using $\mathrm{Cu}-\mathrm{K} \alpha 1$ radiation $(45 \mathrm{kV}, 1.54056 \AA$ А; scan rate of 0.02 degree per s). The morphology and microstructures of the synthesized $\mathrm{Fe}_{3} \mathrm{O}_{4} @$ @CQDs NCs were investigated by transmission electron microscopy (TEM) and high resolution transmission electron microscopy (HRTEM, Jeol/JEM 2100, LaB6) operated at $200 \mathrm{kV}$. Further morphology and composition of $\mathrm{Fe}_{3} \mathrm{O}_{4} @ N C Q D s$ NCs were characterized using field emission scanning electron microscopy (FESEM, Zeiss Ultra-60) equipped with X-ray energy dispersive spectroscopy (EDS). Magnetic property of the material was determined at room temperature using vibrating sample magnetometer (Lakeshore VSM 7410). Composition of the $\mathrm{Fe}_{3} \mathrm{O}_{4} @$ @NCQDs NCs was further confirmed by thermal analysis using thermogravimetric and differential thermal analysis (TGA/DTA) of Perkin Elmer STA 6000 with TG sensitivity of $0.2 \mathrm{mg}$ and DTA sensitivity of $0.06 \mathrm{mV}$.

\subsection{Adsorption studies}

To study adsorption efficiency of $\mathrm{Fe}_{3} \mathrm{O}_{4}$ @NCQDs NCs for representative methyl blue (MB) dye solution from polluted 
water, the usual batch adsorption experiments were carried out using a series of conical flask of $100 \mathrm{~mL}$ capacity under covered conditions to prevent contamination and removal of dye solution from the flask during stirring. The effects of $\mathrm{MB}$ dye concentrations, dosage of $\mathrm{Fe}_{3} \mathrm{O}_{4} @ N C Q D s$ NCs adsorbent, contact time, $\mathrm{pH}$ and temperature were optimized by varying one variable while all other parameters kept constant. For isothermal studies, experiments were performed at 293, 298 and $303 \mathrm{~K}$ with various initial MB dye concentrations and optimum dosage of adsorbent, contact time and $\mathrm{pH}$. The kinetic experiments were performed at optimum dosage, temperature, $\mathrm{pH}$ and dye concentrations at constant time intervals. In the procedure, $100 \mathrm{~mL}$ of $10 \mathrm{ppm}$ dye solution was taken in flask and $50 \mathrm{mg}$ of adsorbent added and stirred at $293 \mathrm{~K}$ temperature. After certain time $(t)$ of adsorption, adsorbent was separated from solution using external magnet and the unadsorbed $\mathrm{MB}$ concentration in the solution was determined using a UV-Vis spectrophotometer at $\lambda_{\max }$ of $664 \mathrm{~nm}$. The MB uptake and percentage adsorption were calculated using eqn (1) and (2).

$$
\begin{gathered}
Q_{\mathrm{e}}=\left(C_{0}-C_{\mathrm{e}}\right) \times V / m \\
\% \text { Adsorption }=\left(\left(C_{0}-C_{\mathrm{e}}\right) / C_{0}\right) \times 100 \%
\end{gathered}
$$

where, $C_{0}$ and $C_{\mathrm{e}}$ are the initial and equilibrium concentrations of dye in $\mathrm{mg} \mathrm{L}^{-1}$. $Q_{\mathrm{e}}$ is the amount of dye in $\mathrm{mg} \mathrm{g}^{-1}$ adsorbed onto unit mass of adsorbent at equilibrium. $V$ is the volume of dye solution in millilitre $(\mathrm{mL})$; and $m$ is the mass of the adsorbent in gram $(\mathrm{g})$.

\section{Results and discussion}

\subsection{Synthesis and characterization}

Fluorescent and highly water soluble nitrogen doped carbon quantum dots (NCQDs) were synthesized by hydrothermal method using lemon juice as precursor and ethylenediamine as coreagent (ESI: Fig. ESI $\dagger$ ). In the process, the chemicals present in lemon juice such as citric acid and ascorbic acid undergoes carbonization forming amorphous graphitic carbon dots and then doped and functionalized by ethylenediamine to form NCQDs. The prepared NCQDs exhibits two typical absorption peaks at $245 \mathrm{~nm}$ and $353 \mathrm{~nm}$ as shown in Fig. 1a (black solid line) which extended with tail to visible region. The first absorption peak at $245 \mathrm{~nm}$ could be assigned to $\pi-\pi^{*}$ transition of aromatic $-\mathrm{C}=\mathrm{C}-$ bonds in the $\mathrm{sp}^{2}$ hybridized domain of graphitic core and the other peak at $353 \mathrm{~nm}$ could be assigned to $\mathrm{n}-\pi^{*}$ transition of $-\mathrm{C}=\mathrm{O}, \mathrm{C}-\mathrm{N}$, or $-\mathrm{C}-\mathrm{OH}$ bonds which may be from hydroxyl $(-\mathrm{COOH})$ or amine $\left(-\mathrm{NH}_{2}\right)$ groups on surface of NCQDs. ${ }^{29}$ The brown yellowish aqueous solution of NCQDs appears brilliant blue under ultraviolet irradiation (inset in Fig. 1(ii)) which indicate the bright luminescence of the prepared NCQDs. In Fig. 1a (blue broken line) indicate the emission spectra of the blue luminescent NCQDs; excitation at $360 \mathrm{~nm}$ and emission at $452 \mathrm{~nm}$.

Information regarding the surface functional group of NCQDs was investigated by Fourier transform infrared spectroscopy (FTIR). As can be seen in the spectrum (Fig. 1b), there are characteristic bands which can indicate the presence of $\mathrm{C}-\mathrm{O}$ bond, $\mathrm{OH}$, aliphatic $\mathrm{C}-\mathrm{H}, \mathrm{N}-\mathrm{H}$ and $\mathrm{C}-\mathrm{N}$ functional groups. The high water solubility of the NCQDs is as a result of these different functional groups on the surface. ${ }^{30-32}$

The morphological properties of NCQDs were confirmed by TEM (Fig. 2a)and as the result indicated, the NCQDs particles are well uniformly distributed quasi-spherical nanoparticles with narrow size distribution in diameter range of 2-9 $\mathrm{nm}$ with an average of $5.5 \mathrm{~nm}$ based on statistical analysis of more than 90 dots (Fig. 2b). The holes in the selected area electron diffraction (SAED) of the NCQDs (inset in Fig. 2 (a)) indicated the particle formation and only two bright spots observed showing the amorphous nature. Paper sheet layer like FESEM image in Fig. 2c confirmed the amorphous nature of NCQDs. Result from elemental composition analysis of EDS spectrum (Fig. ESI3a $\dagger$ ) reveal the presence of $\mathrm{C}, \mathrm{O}$ and $\mathrm{N}$ in the as synthesized material indicating well formation of nitrogen doped carbon quantum dots. X-ray diffraction (XRD) patterns show broad intense diffraction peak centered at $2 \theta=23^{\circ}$ and weak peak at $2 \theta=42^{\circ}$ which assigned to (002) and (101) diffraction pattern of graphitic carbon, as shown in Fig. 2d which indicates the amorphous nature of the NCQDs. ${ }^{33,34}$

The functional group on NCQDs can play key role in preparing $\mathrm{Fe}_{3} \mathrm{O}_{4} @$ NCQDs NCs via coprecipitation method, the
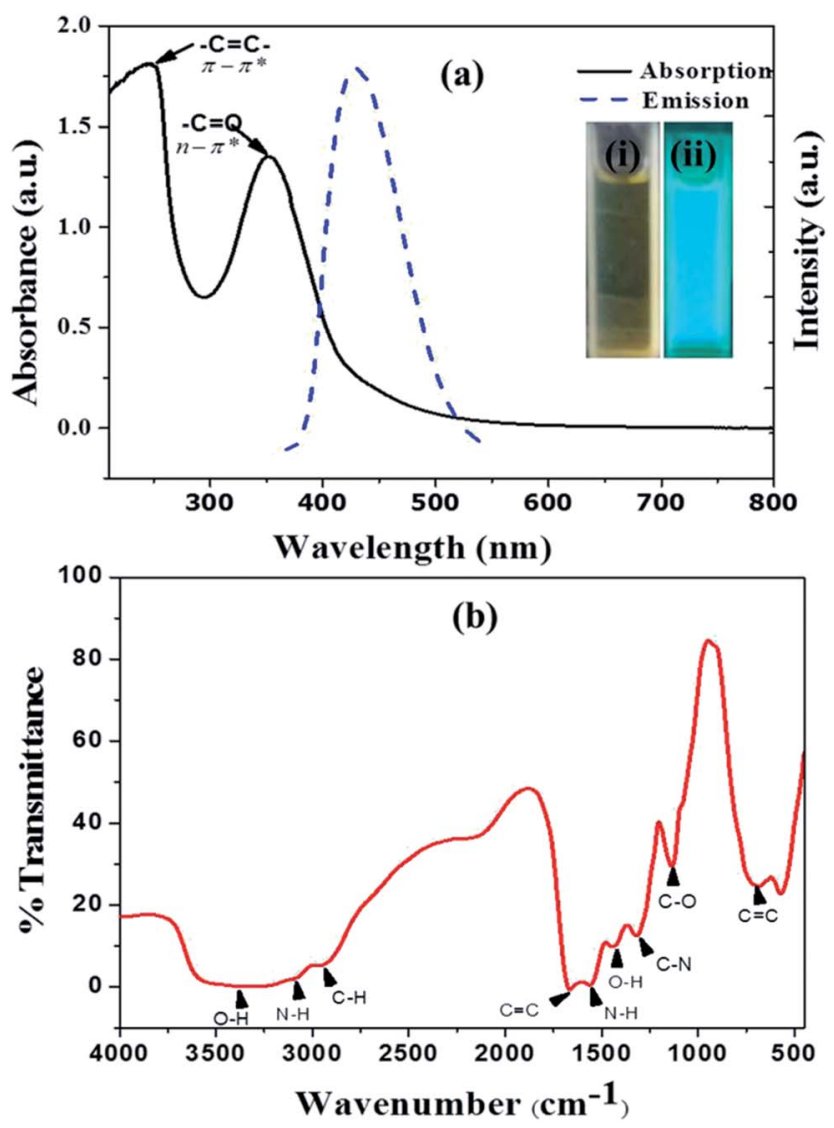

Fig. 1 (a) UV-Vis absorption (solid black line) and emission spectra (blue broken line) inset at right (i) NCQDs solution at day light and (ii) NCQDs solution under ultraviolet radiation, (b) FTIR spectrum of NCQDs. 
presence of NCQDs avoid nucleation stage of coprecipitation and hence aggregation free nanocomposite formed.

A possible plausible formation mechanism of $\mathrm{Fe}_{3} \mathrm{O}_{4}$ @NCQDs NCs via this method is that the carboxylic and amino group on NCQDs chelated with $\mathrm{Fe}^{3+}$ and $\mathrm{Fe}^{2+}$ to form ferric and ferrous complex. In the presence of $\mathrm{NaOH}$, there is also formation of bonds between $\mathrm{OH}^{-}$and $\left(\mathrm{Fe}^{2+}, \mathrm{Fe}^{3+}\right)$. With heating, $\mathrm{HO}^{-} \ldots \mathrm{Fe}^{3+}$ and $\mathrm{OH}^{-} \cdots \mathrm{Fe}^{2+}$ bonds dominate over $\mathrm{COO}^{-} \ldots$ $\mathrm{Fe}^{3+}$ and $\mathrm{COO}^{-} \cdots \mathrm{Fe}^{2+}$ bonds, and as a result ferric hydroxide, $\mathrm{Fe}(\mathrm{OH})_{3}$ and ferrous hydroxide, $\mathrm{Fe}(\mathrm{OH})_{2}$ formed. Ferric hydroxide and ferrous hydroxide dehydrated forming magnetite $\left(\mathrm{Fe}_{3} \mathrm{O}_{4}\right)$ nanoparticle crystals upon heating. The carboxyl and amino group of NCQDs are attached on $\mathrm{Fe}_{3} \mathrm{O}_{4}$ NPs surface through chelation to iron ions. To effectively form $\mathrm{Fe}_{3} \mathrm{O}_{4}$ @NCQD NCs, amino and carbonyl functional groups on surface of NCQDs interact with $\mathrm{COO}^{-} \cdots \mathrm{Fe}^{3+}$ and $\mathrm{COO}^{-} \cdots \mathrm{Fe}^{2+}$ through electrostatic interaction by forming bidentate coordinate covalent bond. As a result stable, relatively aggregate free and uniform sizes $\mathrm{Fe}_{3} \mathrm{O}_{4} @$ @CQDs NCs were formed.

Fig. 3a shows the UV-visible absorption spectra of $\mathrm{Fe}_{3} \mathrm{O}_{4}$ @NCQDs NCs and $\mathrm{Fe}_{3} \mathrm{O}_{4}$ NPs. The UV-visible spectrum show a broad absorption peak at $350 \mathrm{~nm}$ which extended to near IR region, which is primarily due to absorption and scattering of light by $\mathrm{Fe}_{3} \mathrm{O}_{4}$ NPs. ${ }^{14}$ The strong absorption peak around $200 \mathrm{~nm}$ for $\mathrm{Fe}_{3} \mathrm{O}_{4} @ N C Q D s$ NCs ascribed to $\pi-\pi^{*}$ transition of NCQDs, which indicates effective combining of $\mathrm{Fe}_{3} \mathrm{O}_{4}$ NPs and NCQDs.

The FTIR spectra of $\mathrm{Fe}_{3} \mathrm{O}_{4} @ N C Q D s$ NCs synthesised using different proportion of NCQDs depicted in Fig. 3b. FTIR spectra show broad overlapping band around $3360 \mathrm{~cm}^{-1}$, which can be attributed to the $\nu(\mathrm{O}-\mathrm{H})$ and $\nu(\mathrm{N}-\mathrm{H})$ stretching vibration of the hydroxyl and amine group of NCQDs. The band at $1050 \mathrm{~cm}^{-1}$ ascribed to the presence of an alcoholic $\mathrm{C}-\mathrm{O}$ stretching: ${ }^{35}$ The bands at $1624 \mathrm{~cm}^{-1}$ and $1400 \mathrm{~cm}^{-1}$ are ascribed to asymmetric $\left(\nu_{\text {as }}\right)$ and symmetric $\left(\nu_{\mathrm{s}}\right)$ stretching of the $\mathrm{COO}^{-}$respectively. ${ }^{36}$ The band at $1624 \mathrm{~cm}^{-1}$ is also due to the $\mathrm{N}-\mathrm{H}$ bending mode of the amine group coupling with the $\nu_{\text {as }} \mathrm{C}-\mathrm{O}$. The energy
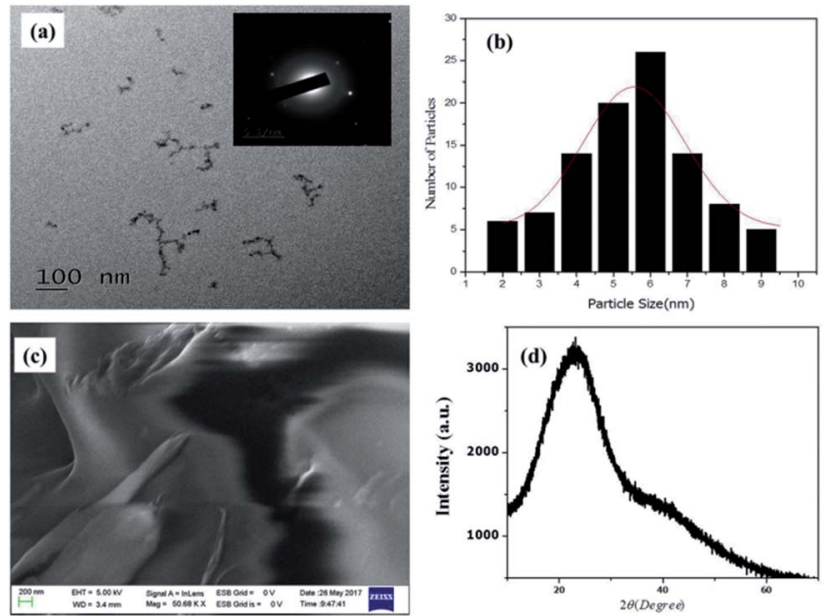

Fig. 2 (a) TEM image (inset SAED) (b) histogram of particle size distribution), (c) FESEM image, (d) XRD of NCQDs. difference $(\Delta \nu)$ between the $\nu_{\mathrm{as}}\left(\mathrm{COO}^{-}\right)$and $\nu_{\mathrm{s}}\left(\mathrm{COO}^{-}\right)$IR bands can reveal the interaction between the carboxylate head and the metal atom. ${ }^{37}$ The $\Delta v\left(1624-1400=224 \mathrm{~cm}^{-1}\right)$ is ascribed to bridging and bidentate coordination, where the interaction between the $\mathrm{COO}^{-}$group and the $\mathrm{Fe}$ atom was covalent. ${ }^{38}$ The characteristic absorption peaks for $\mathrm{Fe}_{3} \mathrm{O}_{4}$ NPs were observed at $580 \mathrm{~cm}^{-1}$ and $418 \mathrm{~cm}^{-1}$ which ascribed to the stretching vibrations of $\mathrm{Fe}^{2+}-\mathrm{O}$ and $\mathrm{Fe}^{3+}-\mathrm{O}$ bonds for $\mathrm{Fe}_{3} \mathrm{O}_{4} \mathrm{NPs}$ respectively. ${ }^{39}$

The crystallite structure of the as prepared NCQDs, $\mathrm{Fe}_{3} \mathrm{O}_{4}$ NPs and $\mathrm{Fe}_{3} \mathrm{O}_{4} @$ @NCQDs NCs were determined by using X-ray diffraction (XRD) technique. Fig. 3d shows the XRD pattern of $\mathrm{Fe}_{3} \mathrm{O}_{4}$ NPs and $\mathrm{Fe}_{3} \mathrm{O}_{4} @$ @NCQDs NCs. The XRD peaks at $2 \theta$ of $18.48^{\circ}, 30.32^{\circ}, 35.64^{\circ}, 38.36^{\circ}, 43.38^{\circ}, 53.76^{\circ}, 57.32^{\circ}, 62.78^{\circ}$, $64.88^{\circ}, 74.30^{\circ}$ and $77.98^{\circ}$ correspond to the diffraction crystallite planes of (111), (220), (311), (222), (400), (422), (511), (440), (530), (622) and (444) respectively in which all peaks indexed to the inverse spinal phase of magnetite (JCPDS file, no. 19-0629). In addition to $\mathrm{Fe}_{3} \mathrm{O}_{4}$ NPs patterns, in the XRD pattern of $\mathrm{Fe}_{3}$ $\mathrm{O}_{4} @ N C Q D s$ NCs (Fig. 3c), there is an additional weak peak at $22.64^{\circ}$ which is characteristic of graphitic NCQDs and can be indexed to the (002) reflection indicating good binding of $\mathrm{Fe}_{3} \mathrm{O}_{4}$ NPs and NCQDs in formation of $\mathrm{Fe}_{3} \mathrm{O}_{4} @ N C Q D s$ NCs. The sharp and strong peaks indicate high crystallinity of the as synthesized $\mathrm{Fe}_{3} \mathrm{O}_{4} @ N C Q D s$ NCs. ${ }^{40}$

Morphological study of the synthesised $\mathrm{Fe}_{3} \mathrm{O}_{4}$ @NCQDs NCs was investigated using FESEM and TEM. As depicted in Fig. 4, FESEM images clearly showed that the $\mathrm{Fe}_{3} \mathrm{O}_{4} @ N C Q D s$ NCs have nearly spherical shape with uniform distribution. The presence of iron (Fe), oxygen (O), carbon(C) and nitrogen (N) in EDS spectrum confirms the successful formation of $\mathrm{Fe}_{3} \mathrm{O}_{4} @ N C Q D s$ NCs.

The representative TEM images of $\mathrm{Fe}_{3} \mathrm{O}_{4} @ N C Q D s$ NCs were presented in Fig. 5a and b. It is clear from TEM images that $\mathrm{Fe}_{3} \mathrm{O}_{4} @ N C Q D s$ NCs have spherical shape without any

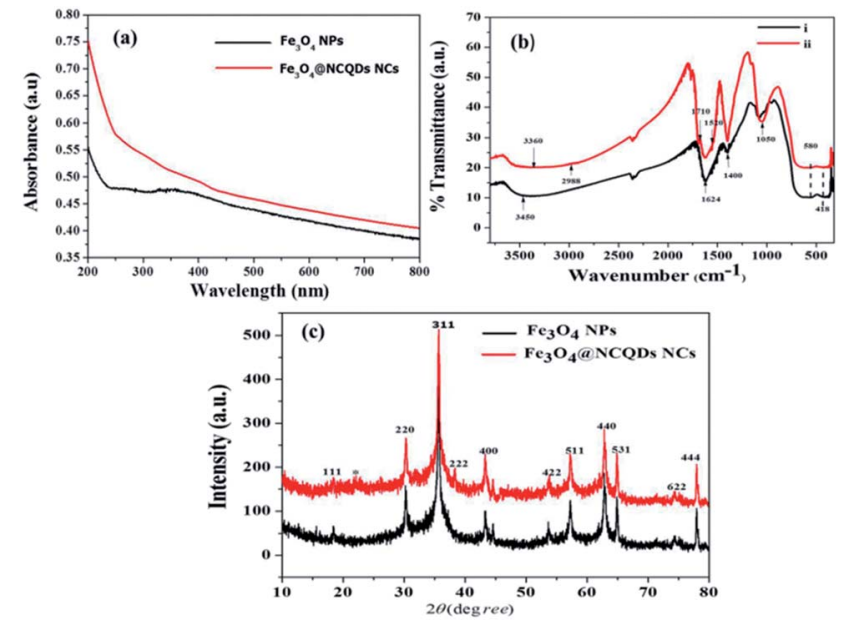

Fig. 3 (a) UV-Vis absorption spectra of $\mathrm{Fe}_{3} \mathrm{O}_{4}$ aNCQDs NCs and $\mathrm{Fe}_{3} \mathrm{O}_{4}$ NPs, (b) FTIR spectra of $\mathrm{Fe}_{3} \mathrm{O}_{4}$ (aNCQDs NCs prepared at different proportion of NCQDs solution (i) 10 times diluted \& (ii) 5 times diluted, and (c) the powder XRD patterns of $\mathrm{Fe}_{3} \mathrm{O}_{4}$ NPs and $\mathrm{Fe}_{3} \mathrm{O}_{4}$ @NCQDs NCs. 

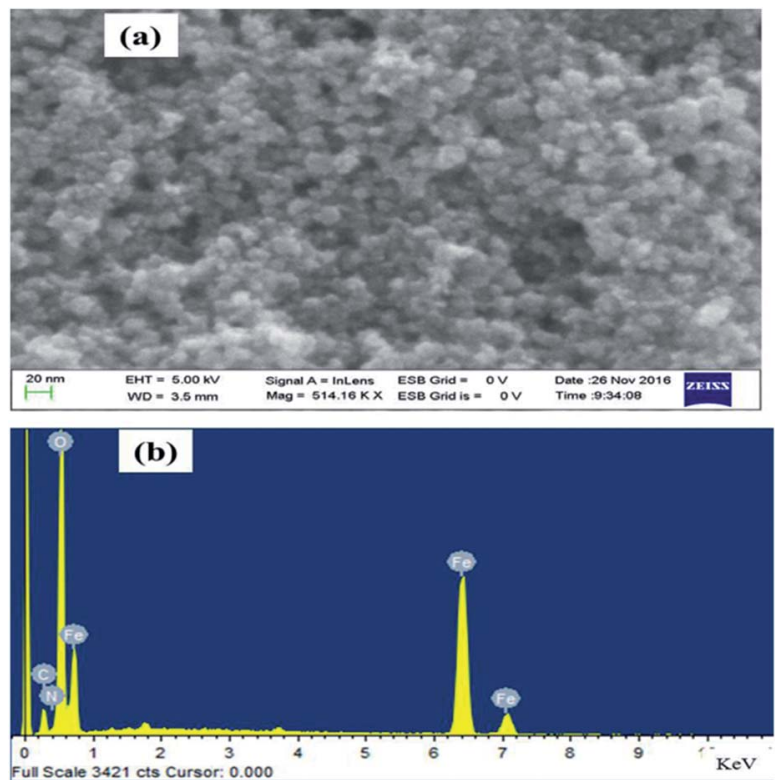

Fig. 4 (a) FESEM image and (b) EDX spectra of $\mathrm{Fe}_{3} \mathrm{O}_{4}$ @NCQDs NCs

aggregation. The particle size distribution of the as synthesized nanocomposites is shown in histogram (Fig. 5d) and the calculated average particle size based on over 100 particles is $5 \mathrm{~nm}$. In addition, crystalline diffraction rings from the selected area diffraction (SEAD) patterns (Fig. 5c) demonstrated that the crystalline nature of the as prepared $\mathrm{Fe}_{3} \mathrm{O}_{4} @$ NCQDs NCs. The inset in Fig. 5a obtained from HRTEM indicates the lattice space $(0.44 \mathrm{~nm})$ which is comparable to XRD results.

\subsection{Optimization of adsorption parameters}

3.2.1 Effect of initial concentration. To optimize this parameter, different concentrations $\left(1.25-15 \mathrm{mg} \mathrm{L}^{-1}\right)$ of $100 \mathrm{~mL}$ MB dye solution were used at (contact time $=20 \mathrm{~min}),(\mathrm{pH}=$ 11), (adsorbent dose $=50 \mathrm{mg}$ ) and (temperature $=298 \mathrm{~K}$ ). The effect of varying concentrations on adsorption is shown in Fig. 6a. The dye removal efficiency of $\mathrm{Fe}_{3} \mathrm{O}_{4}$ @NCQDs NCs was dependent on the initial concentrations of the dye solution in that the maximum adsorption took place at $1.25 \mathrm{mg} \mathrm{L}^{-1}$, which decreased up to $15 \mathrm{mg} \mathrm{L}^{-1}$ from 97.01 to $86.72 \%$ with increasing adsorbate concentration. The decrease in adsorption with an increase in dye concentration could be explained on the basis that $\mathrm{MB}$ removal depends on the availability of the binding sites on the $\mathrm{Fe}_{3} \mathrm{O}_{4} @$ NCQDs NCs adsorbent surface. Total available adsorption sites for a fixed amount of $\mathrm{Fe}_{3} \mathrm{O}_{4} @ N C Q D s$ NCs were used at $7.5 \mathrm{mg} \mathrm{L}^{-1}$ concentration and therefore, $7.5 \mathrm{mg} \mathrm{L}^{-1}$ was taken as optimum initial concentration.

3.2.2 Effect of adsorbent dosage. Optimization of dosage was carried out using 0.1-2.0 $\mathrm{g} \mathrm{L}^{-1}$ of $\mathrm{Fe}_{3} \mathrm{O}_{4} @$ @NCQDs NCs. MB dye concentration, $\mathrm{pH}$, contact time and temperature were $7.5 \mathrm{mg} \mathrm{L}^{-1}, 11.0,20 \mathrm{~min}$ and $298 \mathrm{~K}$, respectively. The effect of dose on percept uptake of $\mathrm{MB}$ onto $\mathrm{Fe}_{3} \mathrm{O}_{4} @$ @NCQDs NCs is shown in Fig. 6b, indicating rapid increase in adsorption with increasing doses. $\mathrm{MB}$ adsorption increased from 60.28 to 94.49\% at dosages of 0.1 and $2.0 \mathrm{~g} \mathrm{~L}^{-1}$ of $\mathrm{Fe}_{3} \mathrm{O}_{4} @ N C Q D s$ NCs
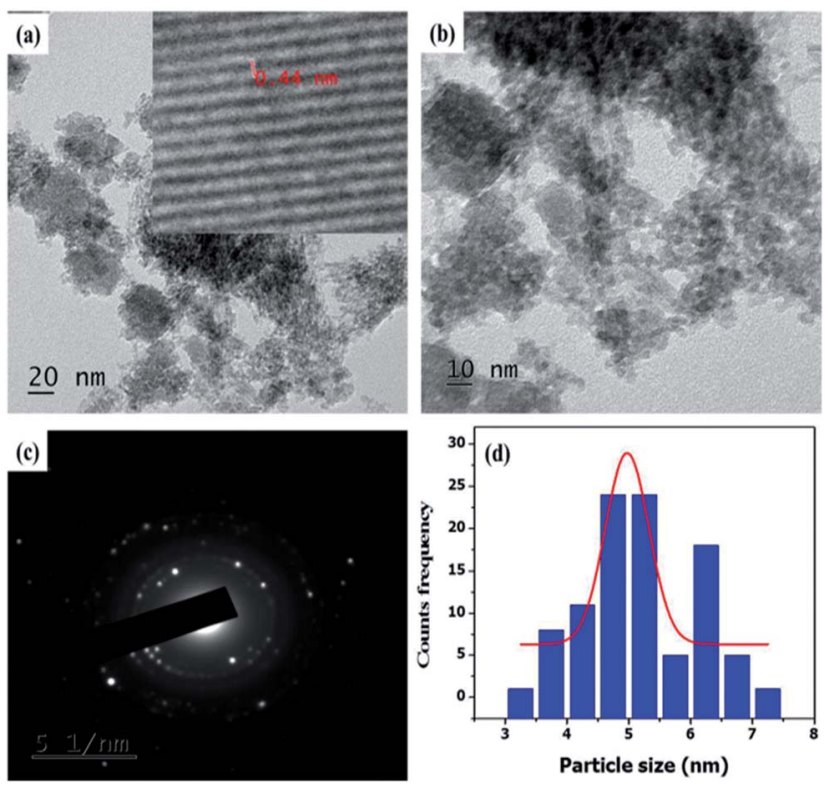

Fig. 5 ( $a$ and b) Representative TEM images (c) SAED and (d) particle size distribution of $\mathrm{Fe}_{3} \mathrm{O}_{4}$ aNCQDs NCs.

adsorbent. Adsorption was $90.84 \%$ at $0.5 \mathrm{~g} \mathrm{~L}^{-1}$ and on further increasing the dose, adsorption percentage was slightly increased with no significance. Therefore, $0.5 \mathrm{~g} \mathrm{~L}^{-1}$ of $\mathrm{Fe}_{3}$ $\mathrm{O}_{4} @$ NCQDs NCs was considered as optimum dosage.

3.2.3 Effect of contact time. Time optimization for the maximum removal of $\mathrm{MB}$ dye onto $\mathrm{Fe}_{3} \mathrm{O}_{4} @$ @NCQDs NCs adsorbent was done by varying contact time (1-40 $\mathrm{min})$. The initial concentration, adsorbent dosage, $\mathrm{pH}$ and temperature were
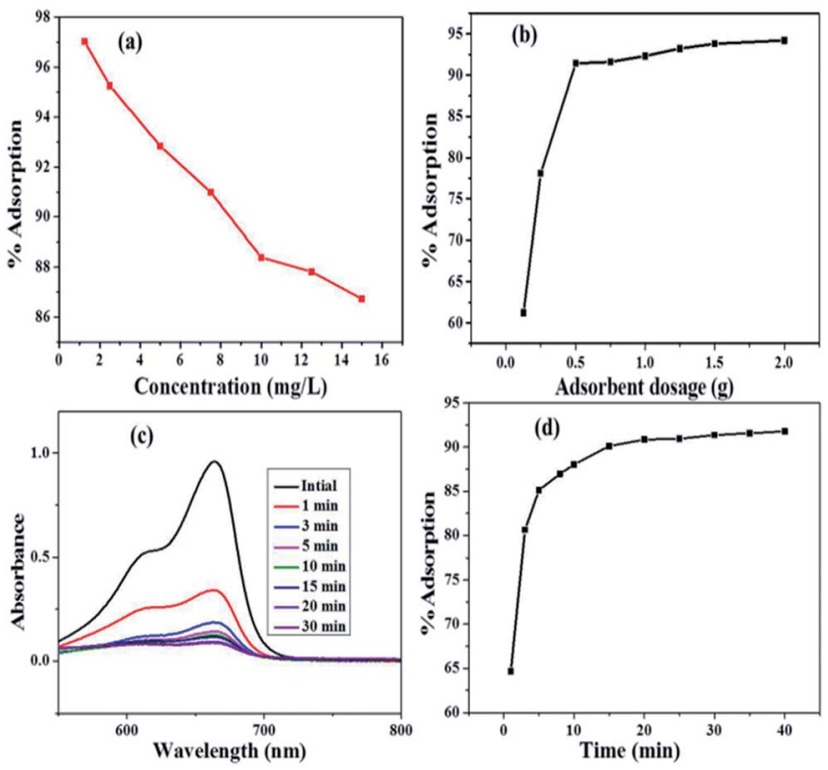

Fig. 6 (a) Effect of initial MB dye concentration on adsorption (b) effect of adsorbent dosage on adsorption (c) UV-Vis absorption spectrum and (d) \% adsorbance of $\mathrm{MB}$ dye $\left(7.5 \mathrm{mg} \mathrm{L}^{-1}\right)$ on $\mathrm{Fe}_{3} \mathrm{O}_{4}$ ( - NCQD NCs (adsorbent dose $=50 \mathrm{mg}$, temperature $=298 \mathrm{~K}, \mathrm{pH}=11$ ) at different time interval. 

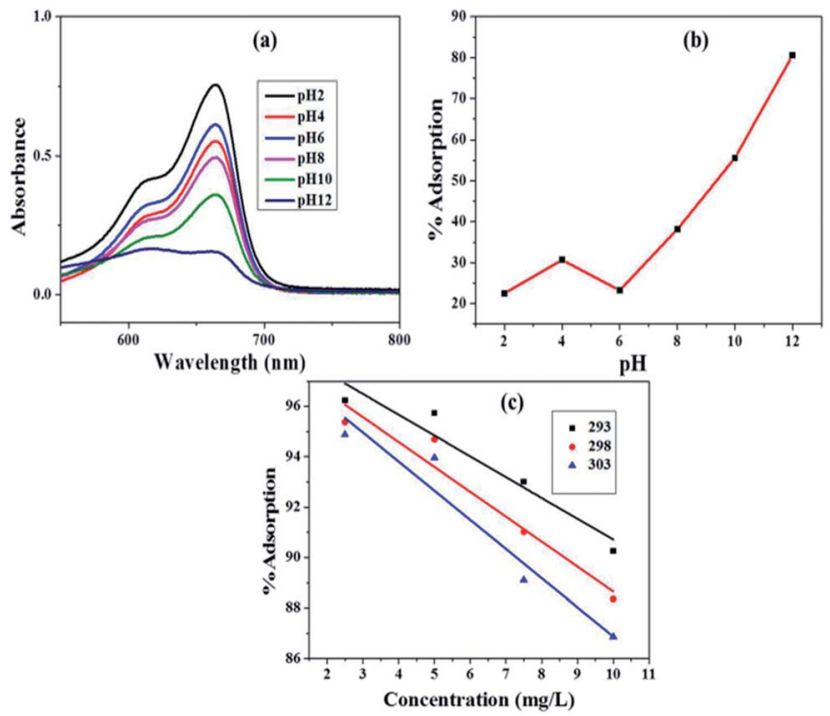

Fig. 7 (a) UV-Vis absorption spectra at different $\mathrm{pH}$ (b) effect of $\mathrm{pH}$ on adsorption and (c) effect of temperature at different concentration on adsorption of $\mathrm{MB}$ on $\mathrm{Fe}_{3} \mathrm{O}_{4}$ (aNCQDs NCs.

$7.5 \mathrm{mg} \mathrm{L}^{-1}, 0.5 \mathrm{~g} \mathrm{~L}^{-1}, 11.00$ and $298 \mathrm{~K}$, respectively. The result showed that adsorption of the $\mathrm{MB}$ dye onto $\mathrm{Fe}_{3} \mathrm{O}_{4} @ N C Q D s$ NCs adsorbent consisted of two phases; initial stage consisting of rapid adsorption (0-15 $\mathrm{min}$ ) and final stage with the relatively slow adsorption rate (Fig. $6 \mathrm{c}$ and d). The adsorption increased from 64.6 to $90.84 \%$ as the contact time was increased from 1 to $20 \mathrm{~min}$. On further increasing the contact time up to $40 \mathrm{~min}$ adsorption increased to $91.78 \%$, but this increase was insignificant and slow. Therefore, $20 \mathrm{~min}$ was considered to be the optimum time for $\mathrm{MB}$ dye adsorption onto $\mathrm{Fe}_{3} \mathrm{O}_{4}$ @NCQDs NCs.

3.2.4 Effect of $\mathbf{p H}$. One of the most governing factors for removal of dye from water using adsorption process is $\mathrm{pH} .{ }^{41}$ The effect of varying $\mathrm{pH}$ (2.0 to 12.0) on the adsorption of $\mathrm{MB}$ onto $\mathrm{Fe}_{3} \mathrm{O}_{4} @ N C Q D s$ NCs was investigated with initial dye concentration of $7.5 \mathrm{mg} \mathrm{L}^{-1}$, catalyst dosage of $0.5 \mathrm{~g} \mathrm{~L}^{-1}$, and contact time of $20 \mathrm{~min}$ at $298 \mathrm{~K}$ (Fig. 7a and b). The $\mathrm{pH}$ of solution was adjusted using $0.1 \mathrm{M} \mathrm{HCl} / \mathrm{NaOH}$. The adsorption capacity increased continuously as the $\mathrm{pH}$ increased from 2-12. At acidic $\mathrm{pH}$, lower adsorption of $\mathrm{MB}$ was observed due to the presence of excess $\mathrm{H}_{3} \mathrm{O}^{+}$ions competing with $\mathrm{MB}$ cations for the available adsorption sites which reduce the adsorbed amount. Therefore, $\mathrm{pH}$ of 11 was selected as optimum $\mathrm{pH}$ for adsorption of $\mathrm{MB}$ dye solution onto $\mathrm{Fe}_{3} \mathrm{O}_{4} @ N C Q D$ NCs.

3.2.5 Effect of temperature. The adsorption studies were carried out at 293, 298 and $303 \mathrm{~K}$, and the results of these experiments are presented in Fig. 7c. The solution temperature was controlled using water bath by using ice as cooling agent. The adsorption decreased almost for all concentrations of methyl blue when temperature was raised from 293 to $303 \mathrm{~K}$. The decrease in adsorption with rise of temperature indicated exothermic nature of the adsorption process.

\subsection{Isotherm modelling of adsorption}

The adsorption data were analyzed by fitting to isotherm models that are Langmuir, Freundlich and Temkin. The isotherm experiments were carried out at 293, 298 and $303 \mathrm{~K}$ with $100 \mathrm{~mL} \mathrm{MB}$ solution of $2.5-10 \mathrm{mg} \mathrm{L}^{-1}$ concentrations, at solution $\mathrm{pH} 11.0$ and adsorbent dosage of $0.5 \mathrm{~g} \mathrm{~L}^{-1}$.

3.3.1 Langmuir isotherm model. The Langmuir model assumes that uptake of adsorbate occurs on a homogeneous surface by monolayer adsorption and that there is no interaction between adsorbent and adsorbate species. ${ }^{\mathbf{4 2 , 4 3}}$ Langmuir mathematical equation is:

$$
C_{\mathrm{e}} / Q_{\mathrm{e}}=C_{\mathrm{e}} / Q_{0}+1 / Q_{0} b
$$

where, $C_{\mathrm{e}}\left(\mathrm{mg} \mathrm{L}^{-1}\right)$ and $Q_{\mathrm{e}}\left(\mathrm{mg} \mathrm{g}^{-1}\right)$ have the usual meanings. $Q_{0}$ (adsorption capacity in $\mathrm{mg} \mathrm{g}^{-1}$ ) is the amount of adsorbate that can be absorbed by a unit mass of the adsorbent for the formation of monolayer on the surface and ' $b$ ' is Langmuir constant, which is related to the affinity between the adsorbent and adsorbate. Both ' $b$ ' and ' $Q_{0}$ ' are characteristics of adsorbent and adsorbate pair. The plot of $C_{\mathrm{e}} / Q_{\mathrm{e}} v s . C_{\mathrm{e}}$ at 293, 298 and $303 \mathrm{~K}$ is shown in Fig. 8a from which ' $Q_{0}$ ' and ' $b$ ' values were evaluated from the slope and intercept of the plots. The values of ' $Q_{0}$ ' were observed to be 24.888, 24.480 and $24.414 \mathrm{mg} \mathrm{g}^{-1}$ at 293, 298 and $303 \mathrm{~K}$, respectively. These values slightly decreased with temperature, which indicated exothermic adsorption of $\mathrm{MB}$ onto $\mathrm{Fe}_{3} \mathrm{O}_{4} @$ NCQDs NCs. The decrease in Langmuir constant, ' $b$ ' values from 2.679 to 1.834 with increase in temperature from 293 to $303 \mathrm{~K}$ indicated lower affinity of $\mathrm{MB}$ for $\mathrm{Fe}_{3} \mathrm{O}_{4} @ N C Q D s$ NCs at higher temperature. The close to unity values of the regression coefficient, $R^{2}(0.946-0.989)$ indicated good fittings of Langmuir isothermal model (ESI: Table ESI $1 \dagger$ ).

A separation factor which also known as dimensionless equilibrium parameter, $R_{\mathrm{L}}$ and its value indicates the adsorption nature: unfavorable if $R_{\mathrm{L}}>1$, linear if $R_{\mathrm{L}}=1$, favourable if $0<R_{\mathrm{L}}<1 .{ }^{44} R_{\mathrm{L}}$ was calculated using the following equation:

$$
R_{\mathrm{L}}=1 /\left(1+b C_{\mathrm{e}}\right)
$$
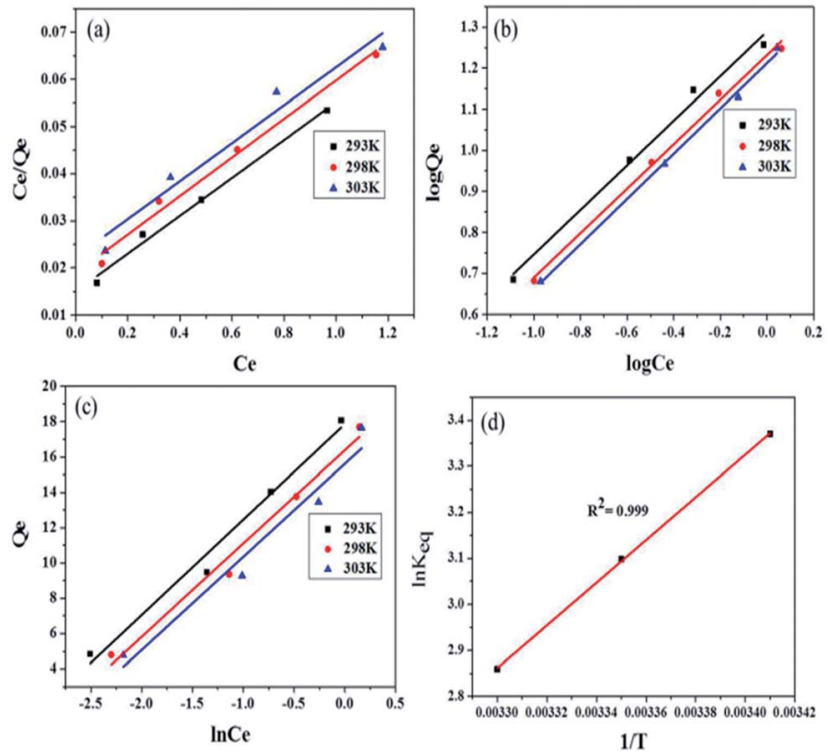

Fig. 8 (a) Langmuir adsorption isotherm plot (b) Freundlich adsorption isotherm plot (c) Temkin adsorption isotherm plot (d) thermodynamic plot of MB dye adsorption onto $\mathrm{Fe}_{3} \mathrm{O}_{4}$ @NCQDs NCs. 
The calculated value of $R_{\mathrm{L}}$ at 293, 298 and $303 \mathrm{~K}$ are 0.436 , 0.428 and 0.414 , respectively, indicating the suitability of $\mathrm{Fe}_{3}$ $\mathrm{O}_{4} @$ NCQDs NCs for adsorption of MB dye solution from waste water.

3.3.2 Freundlich isotherm model. The Freundlich model assumes that the uptake of adsorbate occurs on a heterogeneous adsorbent surface. ${ }^{45}$ The mathematical equation of Freundlich isotherm is expressed as:

$$
\begin{gathered}
Q_{\mathrm{e}}=K_{\mathrm{F}} C_{\mathrm{e}}^{1 / n} \\
\log Q_{\mathrm{e}}=\log K_{\mathrm{F}}+1 / n\left(\log C_{\mathrm{e}}\right)
\end{gathered}
$$

Freundlich constants, $K_{\mathrm{F}}$ (adsorption capacity), and $n$ (adsorption intensity) calculated from the slopes and intercepts of the Freundlich plots, $\log Q_{\mathrm{e}} v s$. $\log C_{\mathrm{e}}$ (Fig. 8b). Magnitude of ' $K_{\mathrm{F}}$ ' can be taken as a relative measure of adsorption capacity of $\mathrm{Fe}_{3} \mathrm{O}_{4} @ N C Q D s$ NCs for the adsorption of MB. The Freundlich constant $n$ (intensity of adsorption) varies with the heterogeneity of the adsorbent and for favourable adsorption ' $n$ ' values should be in the range $1-10 .^{46,47}$

The values of Freundlich constant ' $n$ ' at 293, 298 and $303 \mathrm{~K}$ were $1.838,1.842$, and 1.811 are higher than unity suggesting feasibility of adsorption of $\mathrm{MB}$ onto the surface of $\mathrm{Fe}_{3} \mathrm{O}_{4} @ N C Q D s$ NCs. The values of ' $K_{\mathrm{F}}$ ' were $19.491,17.069$ and $16.317 \mathrm{mg} \mathrm{g}^{-1}$, which clearly showed that ' $K_{\mathrm{F}}$ ' decreased slightly from 293 to 303 $\mathrm{K}$, indicating the decrease in the adsorption capacity at higher temperature. This is in agreement with Langmuir isotherm observations. The regression coefficients were more close to unity as compared to that of Langmuir isotherm showing better fitting of the Freundlich model, which suggest adsorption of MB onto heterogeneous $\mathrm{Fe}_{3} \mathrm{O}_{4} @$ @NCQDs NCs surface.
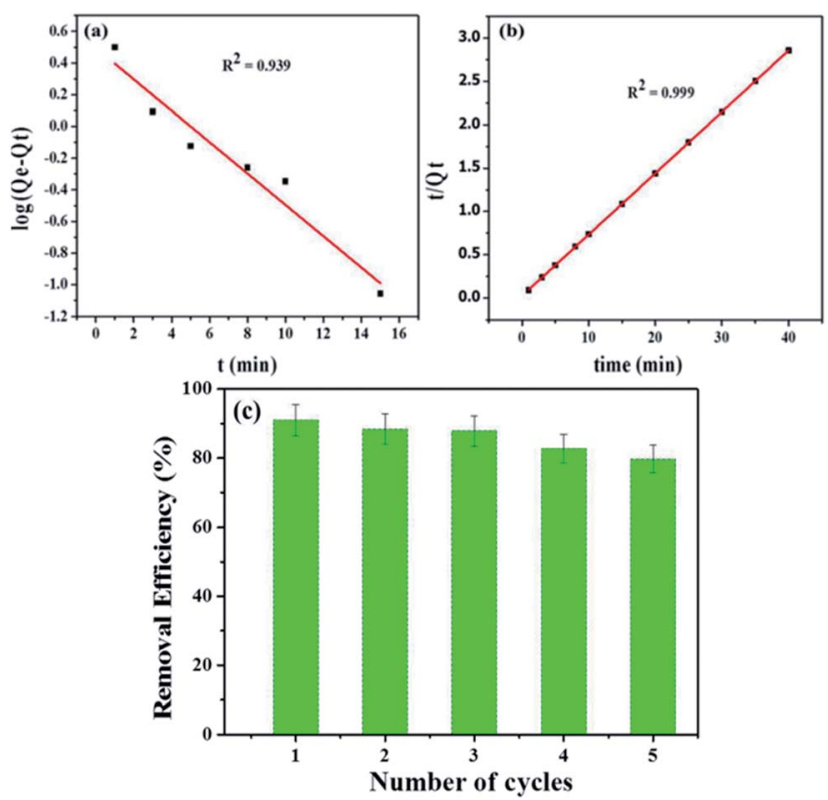

Fig. 9 (a) Pseudo-first order kinetic plot (b) pseudo-second order kinetic plot and (c) The recyclability of the $\mathrm{Fe}_{3} \mathrm{O}_{4}$ @NCQDs NCs in the $\mathrm{MB}$ dye removal from aqueous solution for 5 successive cycles $\left(\mathrm{Fe}_{3}-\right.$ $\mathrm{O}_{4}$ @NCQDs NCs $=50 \mathrm{mg}$ and $\mathrm{MB}=7.5 \mathrm{ppm}$ ).
3.3.3 Temkin isotherm model. Temkin isotherm is based on the assumption that the heat of adsorption of all molecules in layer decreases linearly with coverage of adsorbent surface due to adsorbate-adsorbent interactions. ${ }^{48}$ The mathematical equation of the isotherm is expressed as:

$$
Q_{\mathrm{e}}=R T / b_{\mathrm{T}}\left(\ln A_{\mathrm{T}}+\ln C_{\mathrm{e}}\right)
$$

where, $A_{\mathrm{T}}\left(\mathrm{L} \mathrm{g}^{-1}\right)$ and $b_{\mathrm{T}}\left(\mathrm{kJ} \mathrm{mol}^{-1}\right)$ are Temkin isotherm constants, and ' $R$ ' and ' $T$ ' are the universal gas constant and absolute temperature ( $\mathrm{K})$, respectively. ' $A_{\mathrm{T}}$ ' is the equilibrium binding constant, related to the maximum binding energy and ' $b_{\mathrm{T}}$ ' is a constant related to the heat of adsorption. ${ }^{49}$

The plot of $Q_{\mathrm{e}} v s$. In $C_{\mathrm{e}}$ is shown in Fig. 9c. The constants ' $b_{\mathrm{T}}$ ' and ' $A_{\mathrm{T}}$ ' were calculated from the slope and intercept of the plot, respectively, and are listed in ESI: Table ESI1 $\uparrow$ along with regression coefficients. High magnitudes of ' $A_{\mathrm{T}}$ ' and ' $b_{\mathrm{T}}$ " indicated high interactions between $\mathrm{MB}$ and adsorbent. Therefore, the process might be chemisorption. The values of $R^{2}$ were well close to the unity showing good fitting of the adsorption data to Temkin isotherm model.

\subsection{Thermodynamic studies of adsorption}

Thermodynamic studies are used to describe any reaction in a better way. In this work, thermodynamic studies were performed and the thermodynamic parameters $\left(\Delta G^{\circ}, \Delta H^{\circ}\right.$, and $\Delta S^{\circ}$ ) were determined at 293, 298 and $303 \mathrm{~K}$ temperature using the equations:

$$
\begin{gathered}
K_{\mathrm{eq}}=Q_{\mathrm{e}} / C_{\mathrm{e}} \\
\Delta G^{\circ}=-R T \ln K_{\mathrm{eq}} \\
\ln K_{\mathrm{eq}}=-\Delta H^{\circ} / R T+\Delta S^{\circ} / R
\end{gathered}
$$

where $Q_{\mathrm{e}}$ is solid phase concentration at equilibrium $\left(\mathrm{mg} \mathrm{g}^{-1}\right)$, $C_{\mathrm{e}}$ is equilibrium concentration of dye in solution $\left(\mathrm{mg} \mathrm{L}^{-1}\right)$ and $K_{\text {eq }}$ is equilibrium constant. The calculated free energy change $\left(\Delta G^{\circ}\right)$, enthalpy change $\left(\Delta H^{\circ}\right)$ and entropy change $\left(\Delta S^{\circ}\right)$ parameters at different temperatures are presented in ESI: Table ESI2. $\dagger \Delta H^{\circ}$ and $\Delta S^{\circ}$ values are calculated from the slope and intercept of the linear plots of $\ln K_{\text {eq }} v s .1 / T$, respectively (Fig. 8d). Negative values of $\Delta G^{\circ}$ indicated spontaneity and feasibility while negative values of entropy change $\Delta S^{\circ}$ and enthalpy change $\Delta H^{\circ}$ indicated the exothermic nature of adsorption of $\mathrm{MB}$ dye solution onto $\mathrm{Fe}_{3} \mathrm{O}_{4}$ @NCQDs NCs.

\subsection{Kinetics and mechanism of $\mathrm{MB}$ dye adsorption studies onto $\mathrm{Fe}_{3} \mathrm{O}_{4} @ N C Q D s \mathrm{NCs}$}

The kinetics of adsorption which shows the rate of transport of the dye from solution to the surface of adsorbent was investigated by pseudo-first-order and pseudo-second order kinetic models.

Linearized mathematical form of pseudo-first order model ${ }^{50}$

$$
\log \left(Q_{\mathrm{e}}-Q_{t}\right)=\log Q_{\mathrm{e}}-\left(k_{1} / 2.303\right) \times t
$$


where $k_{1}\left(\mathrm{~min}^{-1}\right)$ is pseudo-first order rate constant, and $Q_{t}$ is the amount $\left(\mathrm{mg} \mathrm{g}^{-1}\right)$ of adsorbate on the adsorbent surface at time $t$. The slope and intercept of straight line plots of $\log \left(Q_{\mathrm{e}}-\right.$ $\left.Q_{t}\right)$ vs. $t$ (Fig. 9a) gave the values of $\left(k_{1}=0.228 \mathrm{~min}^{-1}\right)$ and $Q_{\mathrm{e}}\left(3.125 \mathrm{mg} \mathrm{g}^{-1}\right)$, respectively, and are tabulated in ESI: Table ESI3. $\uparrow R^{2}=0.939$ which is close to unity indicating fitness of pseudo-first order model.

Linearized mathematical form of pseudo-second order model $^{51}$

$$
t / Q_{t}=1 / h+t / Q_{\mathrm{e}}
$$

where $h$ is initial rate constant $\left(h=k_{2} Q_{\mathrm{e}}{ }^{2}\right)$ and $k_{2}$ is overall pseudo-second order constant.

According to the values of correlation coefficient and $Q_{\mathrm{e}}$ (calc.) (ESI: Table ESI $3 \dagger$ ) and Fig. 9b, the pseudo-second order model is found to be more suitable to describe the adsorption kinetic data than the pseudo-first order model for adsorption of MB dye onto $\mathrm{Fe}_{3} \mathrm{O}_{4} @ N C Q D s$ NCs. Hence, it has been confirmed that the adsorption process follows pseudo-second order kinetic behaviour.

\subsection{Recyclability of adsorbent}

$\mathrm{Fe}_{3} \mathrm{O}_{4} @ N C Q D s$ NCs was used as adsorbent for removal of MB from aqueous solution. The used $\mathrm{Fe}_{3} \mathrm{O}_{4} @$ @CQDs NCs can be easily separated from solution at end of application using external magnet. Recyclability of the $\mathrm{Fe}_{3} \mathrm{O}_{4}$ @NCQDs NCs in MB removal was tested for 5 times and the results are depicted in Fig. 9c. The desorption process of MB was conducted by adjusting $\mathrm{pH}$ to 2 using $0.1 \mathrm{M} \mathrm{HCl}$ to remove $\mathrm{MB}$ form surface of $\mathrm{Fe}_{3} \mathrm{O}_{4} @ N C Q D s \mathrm{NCs}$, then washing with acetone. The regenerated $\mathrm{Fe}_{3} \mathrm{O}_{4} @ N C Q D s$ NCs adsorbent was used to evaluate the reusability of the $\mathrm{Fe}_{3} \mathrm{O}_{4} @$ @CQDs NCs for adsorption times. The removal efficiency for the first time $90.8 \%$ decreases to $79.2 \%$ at the fifth cycle. Our results suggested that the $\mathrm{Fe}_{3} \mathrm{O}_{4} @ N C Q D s$ NCs can be reused over 5 times.

\section{Conclusion}

In conclusion, we have developed a cost effective method to prepare spherical shaped $\mathrm{Fe}_{3} \mathrm{O}_{4} @$ @NCQDs NCs using lemon extract as precursor. Superparamagnetic $\mathrm{Fe}_{3} \mathrm{O}_{4}$ @NCQDs NCs have spherical morphology with an average particle size of $5 \mathrm{~nm}$. $\mathrm{Fe}_{3} \mathrm{O}_{4} @$ NCQDs NCs were used as adsorbent removal of MB dye pollutant from aqueous solution. Batch adsorption experiments showed enhanced rapid removal of MB dye within 20 minutes with adsorption efficiency of about $90.84 \%$ at optimum conditions. The adsorption data showed good fitting to Freundlich with $R^{2}$ of 0.993 at $298 \mathrm{~K}$ temperature. The Freundlich constant ' $n$ ' value at $298 \mathrm{~K}$ was 1.842 which suggested the feasibility of adsorption of MB onto the surface of $\mathrm{Fe}_{3} \mathrm{O}_{4} @ N C Q D s$ NCs. Thermodynamic studies indicated the spontaneity and exothermic nature of the adsorption process. From kinetics study, it was found that, the pseudo-second order model is more suitable to describe the adsorption kinetic data than the pseudo-first order model for adsorption of $\mathrm{MB}$ dye onto $\mathrm{Fe}_{3} \mathrm{O}_{4} @$ @CQDs NCs.

\section{Conflicts of interest}

There are no conflicts to declare.

\section{Acknowledgements}

The authors are grateful for the support of the Ministry of Education, Federal Democratic Republic of Ethiopia and Adama Science and Technology University. We are also grateful to Dr P.Shyamala, Department of PNCO, Andhra University for PL studies. Thanks also go to Department of Inorganic and Analytical Chemistry, Andhra University (UGC, India- No. F.540/ 18/DesI/2016(SaI-1) and DST-FIST-India(5R/FIST/CSI-241/ 2012(C).

\section{References}

1 Z. Jabbar, A. Angham and G. Hadi Ferdoos Sami, Orient. J. Chem., 2014, 30, 571-575.

2 D. Kaušpèdienè, A. Gefenienè, E. Kazlauskienè, R. Ragauskas and A. Selskienè, Water, Air, Soil Pollut., 2013, 224, 24.

3 A. Fouda, S. Hassan, M. Azab and E. Saied, Br. Biotechnol. J., 2016, 15, 1-18.

4 S. H. Lin and M. L. Chen, Desalination, 1997, 109, 121-130.

5 K. Shen and M. A. Gondal, J. Saudi Chem. Soc., 2017, 21, S120-S127.

6 M. F. Abid, M. A. Zablouk and A. M. Abid-Alameer, Iran. J. Environ. Health Sci. Eng., 2012, 9, 17.

7 G. E. Üstün, S. K. A. Solmaz and A. Birgül, Resour., Conserv. Recycl., 2007, 52, 425-440.

8 P. K. Malik, J. Hazard. Mater., 2004, 113, 81-88.

9 N. P. Raval, P. U. Shah and N. K. Shah, Appl. Water Sci., 2017, 7, 3407-3445.

10 R. Weissleder, D. D. Stark, B. L. Engelstad, B. R. Bacon, C. C. Compton, D. L. White, P. Jacobs and J. Lewis, AJR, Am. J. Roentgenol., 1989, 152, 167-173.

11 K. Buyukhatipoglu, T. A. Miller and A. M. Clyne, in Biomedical and Biotechnology Engineering, vol. 2, 2008.

12 C. Thammawong, P. Opaprakasit, P. Tangboriboonrat and P. Sreearunothai, J. Nanopart. Res., 2013, 15, 1689.

13 E. Y. Jomma and S.-N. Ding, Sensors, 2016, 16, 243.

14 P. J. Vikesland, R. L. Rebodos, J. Y. Bottero, J. Rose and A. Masion, Environ. Sci.: Nano, 2016, 3, 567-577.

15 A.-H. Lu, E. L. Salabas and F. Schüth, Angew. Chem., Int. Ed. Engl., 2007, 46, 1222-1244.

16 I. Ali, Z. A. AL-Othman and A. Alwarthan, J. Mol. Liq., 2016, 219, 858-864.

17 N. Belachew, D. Rama Devi and K. Basavaiah, J. Exp. Nanosci., 2017, 1-15.

18 W. Shen, M. Shi, M. Wang and H. Chen, Mater. Chem. Phys., 2010, 122, 588-594.

19 X. Liu, Q. Hu, Z. Fang, X. Zhang and B. Zhang, Langmuir, 2009, 25, 3-8.

20 A. K. Mishra and S. Ramaprabhu, Energy Environ. Sci., 2011, 4, 889-895.

21 L. Ai, C. Zhang, F. Liao, Y. Wang, M. Li, L. Meng and J. Jiang, J. Hazard. Mater., 2011, 198, 282-290. 
22 Y.-W. Liu, M.-X. Guan, L. Feng, S.-L. Deng, J.-F. Bao, S.-Y. Xie, Z. Chen, R.-B. Huang and L.-S. Zheng, Nanotechnology, 2013, 24, 025604.

23 R. Mohammad-Rezaei, H. Razmi, V. Abdollahi and A. A. Matin, Anal. Methods, 2014, 6, 8413-8419.

24 M. Shen, Y. Yu, G. Fan, G. Chen, Y. M. Jin, W. Tang and W. Jia, Nanoscale Res. Lett., 2014, 9, 296.

25 K. A. S. Fernando, S. Sahu, Y. Liu, W. K. Lewis, E. A. Guliants, A. Jafariyan, P. Wang, C. E. Bunker and Y.-P. Sun, ACS Appl. Mater. Interfaces, 2015, 7, 8363-8376.

26 K. Hola, Y. Zhang, Y. Wang, E. P. Giannelis, R. Zboril and A. L. Rogach, Nano Today, 2014, 9, 590-603.

27 M. Amjadi, T. Hallaj, H. Asadollahi, Z. Song, M. de Frutos and N. Hildebrandt, Sens. Actuators, B, 2017, 244, 425-432.

28 S. Zhao, D. Xie, X. Yu, Q. Su, J. Zhang and G. Du, Mater. Lett., 2015, 142, 287-290.

29 A. B. Bourlinos, A. Stassinopoulos, D. Anglos, R. Zboril, M. Karakassides and E. P. Giannelis, Small, 2008, 4, 455-458.

30 Z. Yan, J. Shu, Y. Yu, Z. Zhang, Z. Liu and J. Chen, Luminescence, 2015, 30, 388-392.

31 X. T. Zheng, A. Ananthanarayanan, K. Q. Luo and P. Chen, Small, 2015, 11, 1620-1636.

32 Z.-X. Wang and S.-N. Ding, Anal. Chem., 2014, 86, 7436-7445.

33 A. Hao, X. Guo, Q. Wu, Y. Sun, C. Cong and W. Liu, J. Lumin., 2016, 170, 90-96.

34 Q.-Y. Cai, J. Li, J. Ge, L. Zhang, Y.-L. Hu, Z.-H. Li and L.-B. Qu, Biosens. Bioelectron., 2015, 72, 31-36.

35 N. Song, X.-L. Wu, S. Zhong, H. Lin and J.-R. Chen, J. Mol. Liq., 2015, 212, 63-69.

36 H. Gupta, P. Paul, N. Kumar, S. Baxi and D. P. Das, J. Colloid Interface Sci., 2014, 430, 221-228.
37 N. Belachew, D. Rama Devi and K. Basavaiah, J. Mol. Liq., 2016, 224, 713-720.

38 F. Ozel and H. Kockar, J. Supercond. Novel Magn., 2016, 30, 2023-2027.

39 A. Akhundi and A. Habibi-Yangjeh, Mater. Chem. Phys., 2016, 174, 59-69.

40 R. P. Araújo-Neto, E. L. Silva-Freitas, J. F. Carvalho, T. R. F. Pontes, K. L. Silva, I. H. M. Damasceno, E. S. T. Egito, A. L. Dantas, M. A. Morales and A. S. Carriço, J. Magn. Magn. Mater., 2014, 364, 72-79.

41 A. A. Inyinbor, F. A. Adekola and G. A. Olatunji, Water Resources and Industry, 2016, 15, 14-27.

42 I. Langmuir, J. Am. Chem. Soc., 1916, 38, 2221-2295.

43 G. Crini and P.-M. Badot, Sorption Processes and Pollution: Conventional and Non-conventional Sorbents for Pollutant Removal from Wastewaters, Presses Univ. Franche-Comté, 2010.

44 C.-J. Sun, L.-Z. Sun and X.-X. Sun, Ind. Eng. Chem. Res., 2013, 52, 14251-14260.

45 W. Rogers and M. Sclar, J. Phys. Chem., 1931, 36, 2284-2291. 46 T. A. Khan, S. A. Chaudhry and I. Ali, J. Mol. Liq., 2015, 202, 165-175.

47 T. K. Saha, J. Water Resour. Prot., 2010, 02, 898-906.

48 A. O. Dada, A. P. Olalekan, A. M. Olatunya and O. Dada, IOSR J. Appl. Chem., 2012, 3, 38-45.

49 R. R. Sheha and E. Metwally, J. Hazard. Mater., 2007, 143, 354-361.

50 J.-P. Simonin, Chem. Eng. J., 2016, 300, 254-263.

51 Y. S. Ho and G. McKay, Process Biochem., 1999, 34, 451-465. 